\title{
Banking Information Success Acceptance: An Empirical Evaluation
}

Ziqi Liao, Hong Kong Baptist University, Hong Kong

Raymond Landry Jr., (E-mail: raylandry@ panam.edu), University of Texas, Pan America

Michael Tow Cheung, University of Hong Kong, Hong Kong

\begin{abstract}
Extending the technology acceptance model, we present a two-level analysis to empirically evaluate the acceptance of business information systems in customer-based retail banking. Utilizing survey data from a representative banking group in a representative international financial center, regression analysis first indicated that end-user satisfaction, usage and acceptance depend significantly on the system's perceived usefulness, perceived ease of use and expected ability to meet customer information requirements. In turn, these perceptual-anticipatory considerations were found to be positively and significantly affected by technical-functional factors in the form of user-friendliness and system reliability. For the corporate strategist, our empirical results suggest enhancing perceived ease of use, perceived usefulness and ability to meet customer information needs in order of importance when introducing or up-grading information systems in retail banking and other service-based business activities.
\end{abstract}

\section{Introduction}

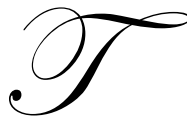

he business environment is undergoing rapid and continuous transformation, primarily as a result of increased globalization, heightened awareness and expectations on the part of consumers and regulators, shifts in the supply side and technology, and changes in the social and political structure. In parallel, market and institutional dynamics have emerged in which private and public firms and organizations are subject to strong and relentless pressure to enhance efficiency, product-service quality and competitiveness, with strategies such as business process reengineering (BRP) being introduced in support. The driving force behind many of these developments is information technology (IT) which lies at the core of some of the most innovative and effective initiatives introduced by firms and organizations to succeed or survive.

The majority of firms and organizations in economically developed countries and regions have computerized business processes and the remainder is not far behind. Consider, for example, bank teller operations. As the most visible point of reference in retail banking, tellers enter as an essential input into the customer service equation. Yet these individuals are difficult to re-train or to upgrade, being among the least endowed in human capital. IT offers a solution to this problem. In retail banking, managers now focus on exploiting business information systems (BIS) to enhance human resources, improve service delivery, increase efficiency, reinvent business processes, and to develop strategies to attain and maintain competitive advantage.

In firms or organizations enjoying information technology acceptance and positive impact on user satisfaction, optimally integrated and utilized BIS can effectively assist problem solving, unlock creativity, facilitate BRP, and enhance product-service quality and productivity. The more the firm or organization relies on IT, the more important it is to analyze its high-touch aspects - viz., the people side. The present study involves a major Singaporean financial institution with offices and branches all over the world. We model and empirically evaluate the acceptance of a new BIS designed to support retail banking services in terms of the direct and indirect effects on people - in particular, the

Readers with comments or questions are encouraged to contact the authors via email. 
perceptions and expectations of staff and customers regarding the following factors and variables grouped in two levels: usefulness, ease of use, ability to meet customer information needs, user-friendliness, system reliability, and end-user satisfaction. It was found that user-friendliness and system reliability exerted positive and statistically significant first-level effects on perceived usefulness, perceived ease of use and expected ability to meet customer information needs, while perceptions and expectations regarding usefulness, ease of use and the ability to meet customer information needs emerged as the statistically most important second-level determinants of end-user satisfaction and therefore, the intention to use and accept the new BIS.

The BIS under study was mainly designed and introduced to enhance customer-based retail banking functions and services. Executives and staff from the bank's Singapore offices and branches participated in a survey to solicit information regarding end-user satisfaction, user-friendliness, system reliability, perceived usefulness, perceived ease of use, expected ability to meet customer information needs, and their direct and indirect effects on system acceptance. Since many articles on BIS acceptance employ a qualitative approach, incommensurable conclusions are often found in the literature. It is suggested that the quantitative approach would be more useful if more precise and comparable conclusions and implications under clearly specified ceteris paribus conditions are desired, both for intrinsic interest and as a basis for further research.

\section{Background}

The financial institution studied was one of Singapore's leading universal banking groups with some 300 offices and branches worldwide. The parent institution enjoyed a Moody's 'B' rating for overall financial strength and Aa2 and prime-1 ratings for long- and short-term deposits. A full range of financial and commercial services was offered, from retail and wholesale banking, derivatives trading, factoring, fund management, hire purchase, insurance, merchant and private banking, precious metals trading, stock-brokering, trust services, venture capital investment, hotel management, leasing, pharmaceuticals and property development to travel services. Over the first half of the year of survey (2000) the group enjoyed growth rates of $12 \%$ and $28 \%$ respectively in total income and net profit and a return on equity of $13 \%$ suggesting that operations have returned to normal after the Asian financial crisis.

In its application of IT, the corporate strategy was to direct technology towards specific functional areas. From 1996 to 2000 some US $\$ 45$ million was invested along these lines, the bulk on a back-end customer-based BIS to enable (through relational databases) interactive retail banking and high activity volumes over the Internet. A fully integrated lending subsystem was launched in June 2000, which aimed to shorten preparation time for credit applications by as much as $30 \%$ and to save an expected US $\$ 8$ million per year. To support sales and marketing, a parallel subsystem was introduced to allow customer value indices to be computed on the basis of inputs from a data warehouse.

\section{System Evaluation}

The successful implementation of IT in firms and organizations has been the subject of numerous investigations in the literature. In particular, the technology acceptance model or TAM, first proposed by Davis $(1986,1989)$, has been widely applied in this research. According to the theory of reasoned action, individual beliefs influence attitudes, which lead to intentions, which then produce behavior (Fishbein and Ajzen 1975). Under the TAM, this belief-attitude-intention-behavior relationship is applied to analyze IT acceptance with the goal of "providing an explanation of the determinants of [information technology] acceptance that is general, capable of explaining user behavior across a broad range of end-user computing technologies and user populations, while at the same time being both parsimonious and theoretically justified" (Davies 1989). The theory's basic constructs are perceived usefulness and perceived ease of use, defined respectively as "the degree to which a person believes that using a particular system would enhance his or her job performance," and as "the degree to which a person believes that using a particular system would be free of effort" (op. cit.). Expectancy theory, which explores the importance of beliefs in decision-making, also lends support to the roles assigned to perceived usefulness and perceived ease of use. The TAM was first successfully tested in a longitudinal study of behavioral intentions to use a computer system (Davis, Bagozzi and Warshaw 1989). In particular, perceived usefulness was found to exert a strong positive influence on intentions while perceived ease of use produced a smaller but still significant direct effect which subsided over time. Since that time, numerous 
applications and extensions of the TAM have been published. (See e.g. Straub, Limayen and Karahanna-Evaristo 1995, Dishaw and Strong 1999, Lucas and Spitler 2000, Venkatesh and Davies 2000, Plouffe, Hulland and Vanderbosch 2001.)

\section{The BIS Success Model and Hypotheses}

Under TAM, IT acceptance is evaluated in terms of behavioral intention to use and actual usage that in turn are determined by user perceptions towards usefulness and ease of use. We adapt this analysis to the case of the new BIS noted above. Acceptance is proposed to depend positively on end-user perceptions regarding usefulness, ease of use and - because of the system's customer-service orientation - by the expected ability to meet the information needs of (retail) account holders. In turn, these perceptual-anticipatory factors are positively affected by (increased) user-friendliness and system reliability, which represent the efficiency and performance gains from new technology. Fig. 1 displays a schematic representation of the extended TAM, in which arrows denote the direction of causal relationships. In particular, user-friendliness and system reliability enter firstly on the technical-functional level to positively determine perceived usefulness, perceived ease of use and expected ability to meet customer information needs, while in the second perceptual-anticipatory level end-user satisfaction is theorized to depend positively on perceived usefulness, perceived ease of use and expected ability to meet customer information needs which then exerts a direct effect on intention to use, system usage and BIS acceptance.

Figure 1: The BIS Success Model

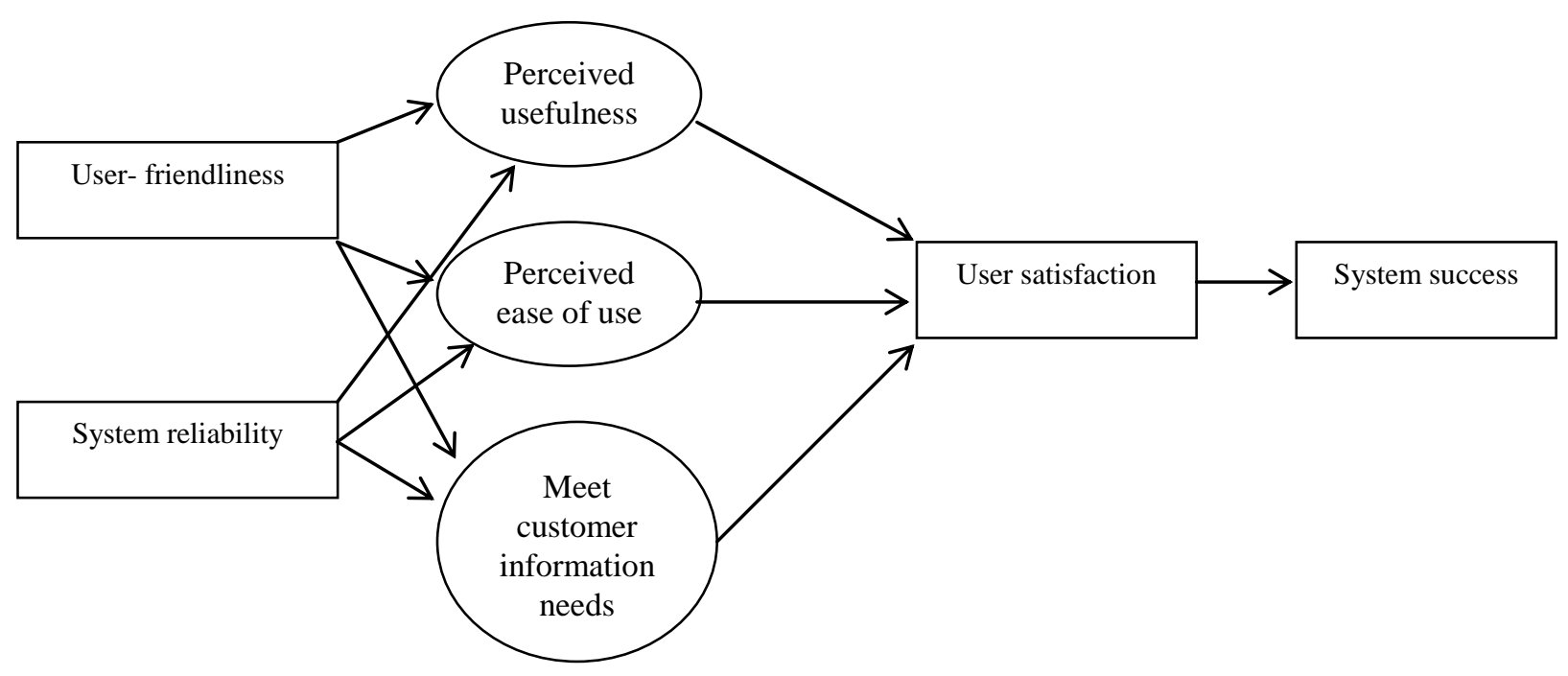

User-friendliness

System reliability

Perceived usefulness

Perceived ease of use

Meet customer information needs

User satisfaction

System success
The new BIS is designed for end-user convenience The new BIS functions reliably

The new BIS is perceived to be useful in the TAM sense

The new BIS is easily applicable in the TAM sense The new BIS can meet customer information needs End-users are satisfied with the new BIS

The new BIS is accepted 


\subsection{User-Friendliness}

As a determinant of IS acceptance, user-friendliness is present when individuals are able to operate the system without constant recourse to external technical assistance and without high stress and strain and the implied costs (Laudon and Laudon 2002). Since complexity deters usage, user-friendly IS should also encourage interaction through learning-by-doing thereby enabling the firm or organization to reduce expenditure on learning and training. User-friendliness is generally evaluated along two dimensions: users' handling of the system with minimum difficulty per unit time, and the availability of productivity tools (e.g. hardware, software and peripheral devices) in support. In the present case, since the target population consisted of bank staff utilizing a new BIS in the course of work, the following functions and considerations were proposed to assess actual and expected user-friendliness.

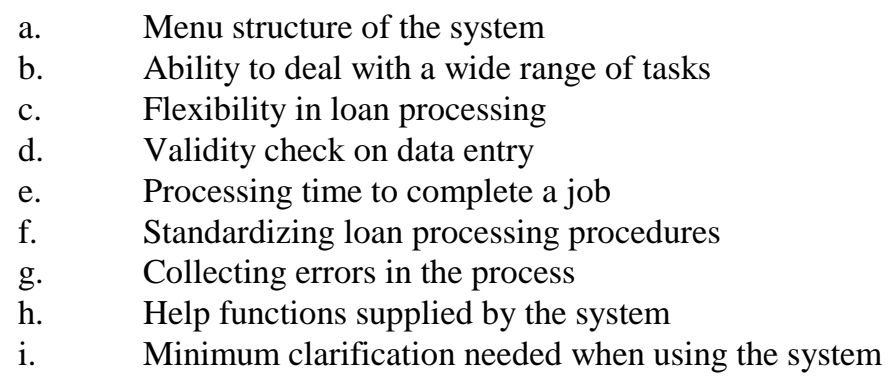

\subsection{System Reliability}

System reliability refers to its ability to support continuous and smooth functions and operations according to its own design (Ein-Dor and Jones 1985, Laudon and Laudon 2002). Applied to retail banking, the reliable use of IT would enhance product delivery and increase efficiency through the consistent and continuous supply of timely, meaningful and unambiguous information by the reduction of errors and system breakdown, and by services and requests being performed as required the first time round. Accordingly, the following functions and considerations were introduced to assess the actual and expected reliability of the new BIS:
a. System downtime
b. Well-documented trouble shooting procedures
c. Data accuracy
d. Minimizing system breakdown
e. Reduction in errors
f. Elimination of the possibility of making errors
g. Vendor backup support

\subsection{Perceived Usefulness and Perceived Ease of Use}

Under TAM, perceived usefulness follows when users feel that the IS in question would increase their ability to expedite job tasks and requirements with increased efficiency and effectiveness. In the present survey, the following functions and considerations were proposed to measure this construct.
a. Rationalizing processing procedures in retail banking
b. Enhancing efficiency in processing
c. Provision of useful tools to evaluate loan etc. applications
d. Ability to identify and process non-standard requirements

Hypothesis H1 was then introduced to empirically test the relationships between perceived usefulness, user-friendliness, and system reliability: 
$\mathbf{H}_{1}$ : The perceived usefulness of the new BIS depends positively on user-friendliness and system reliability.

Since perceived ease of use is generally measured in terms of the (subjective) probability that users would find the IS can be used easily in the sense of minimized effort, a measurement based on the following functions and considerations was employed in the survey:

a. The new BIS can be learned easily

b. Reduction in demand for computing skills

c. Minimization of training time

d. $\quad$ Customer records can be retrieved quickly and at low cost

e. Loan assessments can be referenced efficiently

Accordingly, we proposed hypothesis $\mathrm{H} 2$ as follows:

$\mathbf{H}_{2}$ : The perceived ease of use of the new BIS depends positively on user-friendliness and system reliability.

\subsection{Customer Information Needs}

Since it is generally recognized that customer satisfaction is crucial for product differentiation and competitive advantage, its measurement and enhancement strategies have been prime concerns in quality management and business performance assessment. (See e.g. Bailey and Person 1983, Garvin 1988, Eccles 1991, Feigenbaum 1991, Myers 1997). In the highly competitive retail banking sector, the provision of information to clients on demand is a vital factor in survival and growth. Applying the extended TAM, we propose that customer satisfaction can be interpreted in terms of the realization of expectations regarding the BIS's ability to meet the needs and requirements noted above. Since it would be difficult to contact and interview retail account holders directly, we targeted the bank's marketing officers as individuals best informed about customer preferences to be proxies in the survey. After reminding these individuals to separate out answers of this nature from statements regarding self-satisfaction, the following questions were employed to assess expectations as to whether customers' information needs would be met by the new BIS:

a. Customer enquiries are answered quickly

b. $\quad$ Efficient selection of information to meet customers' needs

c. Appropriately detailed information is supplied

d. Accurate information is supplied

e. Ability to accept more customer enquiries

f. Customer complaints are quickly resolved

g. Minimization of customer complaints

h. Maintenance of cordial customer relationships

i. $\quad$ Comprehensive handling of customer requests

Based on the above considerations, hypothesis $\mathrm{H} 3$ was proposed as follows:

$\mathbf{H}_{3}$ : User-friendliness and system reliability contribute positively to the system's expected ability to meet customer information needs and requirements.

\subsection{End-user Satisfaction}

The idea of explicitly incorporating user attitudes in IS acceptance was introduced by Lucas (1972). In organizational behavior theory, user satisfaction has traditionally been considered to be a major factor determining successful system implementation. (See e.g. Powers and Dickson 1973, Ives and Olson 1984, Raymond 1987, Abdul-Gader 1992, 1996). We therefore submit that under the extended TAM, staff satisfaction positively affects system usage and acceptance of the bank's new BIS. This proposition derives support from attitude theory and the findings 
that employee attitudes are related strongly to IS success and that user satisfaction represents a valid measure of system effectiveness (Baroudi, Olson and Ibes 1986, Gatain 1994).

In the present study, end-user satisfaction can be readily measured by staff perceptions regarding the short-term ability of new BIS to support and improve retail banking operations, and the system's perceived long-term ability to enhance future job status and career prospects. In particular, job satisfaction in its intrinsic, extrinsic, and overall aspects were taken into account in the questionnaire. The first factor referred to satisfaction derived from the work itself (such as feelings of accomplishment and personal growth). The second referred to the benefits associated with doing the job (mainly pay, promotion and work conditions) while the third factor was concerned with general aspects (such as a congenial working environment). In addition, we sought information from supervisors regarding the extent to which they felt the new BIS would improve staff productivity and quality of work, over and above their own improvements in these areas.

Accordingly, respondents were presented with the following questions to measure end-user satisfaction regarding the new BIS:

a. A rise in job status for users

b. Better career prospects

c. Provision of a more autonomous work environment

d. Heightened end-user feelings of control

e. Minimization of extraneous considerations in retail banking functions, especially in loan processing

f. Creation of a cooperative working environment

g. Improvement in inter-colleague communications

h. Improvement in productivity

i. Enhancement of work quality

The path-analytical approach of Figure 1 suggests that we should examine whether perceived usefulness and perceived ease of use and expected ability to meet customer information needs jointly exert a positive impact on user satisfaction from the new BIS. Hypothesis H4 is therefore introduced as follows:

$\mathbf{H}_{4}$ : User satisfaction depends jointly and positively on perceived usefulness, perceived ease of use, and expected ability to meet customer information needs.

\subsection{System Success}

Following DeLone (1988), Davis (1989), Soh, Yap and Raman (1992), Adams, Nelson and Todd (1992), Straub, Limayen and Karahanna-Evaristo (1995) and Szajna (1996), we measure BIS acceptance in terms of usage. Since it has been demonstrated that "system usage has a notable practical value for managers interested in evaluating the impact of information technology" (Straub et. al., op. cit.), we also submit that the more individuals are satisfied with the system the more frequently they would use it. Therefore, end-user satisfaction directly contributes to the acceptance and successful implementation of the bank's new BIS. To test this proposition, we present:

$\mathbf{H}_{5}$ : End-user satisfaction exerts a positive impact on the acceptance of the new BIS and its successful implementation.

\section{Research Models and Methodology}

Corresponding to Figure 1 and the extended TAM, we introduce a two-level approach to empirically evaluate the user acceptance of the new BIS. In level one, three regression sub-models are employed to test hypotheses H1, H2 and $\mathrm{H} 3$ by estimating the impact of user-friendliness and system reliability on (respectively) perceived usefulness, perceived ease of use, and expected ability to satisfy customer information needs. 


\subsection{Level 1 Sub-Models}

1. $\quad$ USEFULNESS $=\alpha_{1}+\beta_{11}$ USERFRIENDLY $+\beta_{12}$ RELIABILITY $+u_{1}$

2. $\quad$ EASEOFUSE $=\alpha_{2}+\beta_{21}$ USERFRIENDLY $+\beta_{22}$ RELIABILITY $+u_{2}$

3. $\quad$ CUSTOMER $=\alpha_{3}+\beta_{31}$ USERFRIENDLY $+\beta_{32}$ RELIABILITY $+u_{3}$

where:

USEFULNESS is the perceived usefulness of the new BIS as defined above and as measured by the survey data, EASEOFUSE is the perceived ease of use of the new BIS as defined above and as measured by the survey data, CUSTOMER is the expected ability of the new BIS to meet customer information needs as defined above and as measured by the survey data,

USERFRIENDLY is the user friendliness of the new BIS as defined above and as measured by the survey data, RELIABILITY is the system reliability of the new BIS as defined above and as measured by the survey data.

Given that user-friendliness and system reliability enter as exogenous variables in level one, (1), (2) and (3) can be interpreted as reduced forms. It is therefore possible to apply a computationally convenient method like ordinary least squares (OLS) to estimate the equation coefficients.

\subsection{Level 2 Sub-Models}

On the second level, we introduce two regression sub-models to test hypotheses $\mathrm{H} 4$ and H5:

4. $\quad$ USERSATISFY $=\alpha_{4}+\beta_{41}$ USEFULNESS $+\beta_{42}$ EASEOFUSE $+\beta_{43}$ CUSTOMER $+u_{4}$

5. $\quad$ SYSTEMSUCCESS $=\alpha_{5}+\beta_{51}$ USERSATISFY $+u_{5}$

where:

USERSATISFY is end-user satisfaction from the new BIS as defined above and as measured by the survey data, SYSTEMSUCCESS is user acceptance of the new BIS as defined above and as measured by the survey data.

Given that perceived usefulness, perceived ease of use and expected ability to meet customer information needs enter as exogenous variables in level two, (4) and (5) can be interpreted as reduced forms. As before, it is then possible to apply a computationally convenient method like OLS to estimate the equation coefficients.

To introduce the project, a preliminary meeting was arranged with the bank's Department of Consumer Services. In particular, we sought permission and participation in an empirical study of acceptance for the group's new BIS that as noted above was mainly intended to facilitate customer-based retail banking functions and services. The management reacted positively and agreed to an internal survey of departments most closely involved in computer-based operations. Additional staff feedback was obtained, after which the design of a questionnaire with subsections specialized to different task and functional groups was finalized. The questionnaire together with an accompanying cover letter, which stated the purpose and nature of the research, was distributed through the bank's internal mail service to five local departments in Singapore with a total of 80 employees. The participation was voluntary under confidentiality. Meaningfully completed questionnaires were received from 60 employees translating into a high response rate of $75 \%$.

Our questionnaire solicited information regarding the variables and factors contained in Figure 1: user-friendliness, system reliability, expected ability to meet customer information needs, perceived usefulness, perceived ease of use, end-user satisfaction, and system success. To minimize demands on time and effort, sub-sections devoted to specific business functions were designed for each task group or department. In particular, questions were presented to relevant end-users to conduct a post-evaluation of the new BIS. Respondents were invited to indicate agreement or disagreement in terms of a seven-point Likert-scale with calibration according to the following equiva- 
lences: 1: very strongly disagree, 2: strongly disagree, 3: disagree, 4: neutral, 5: agree, 6: strongly agree, 7: very strongly agree (Aaker, Kumar and Day 2001).

\section{Empirical Results}

To obtain an overview of user perceptions toward the various factors and variables under study, we first computed descriptive statistics from the survey data (Table 1).

Table 1 Descriptive Statistics

\begin{tabular}{lcc}
\hline Survey Variable & Mean & Std Dev \\
\hline USERFRIENDLY & 5.7067 & 0.6789 \\
SYSTEMRELIABILITY & 5.6220 & 0.5207 \\
PERCEIVED USEFULNESS & 6.2167 & 0.5318 \\
PERCEIVED EASEOFUSE & 6.1833 & 0.7247 \\
CUSTOMER & 6.0737 & 0.6791 \\
USERSATISFY & 6.1200 & 0.7152 \\
SYSTEMSUCCESS & 6.5000 & 0.6244 \\
\hline
\end{tabular}

In particular, the mean Likert score of $>6$ ('strong agreement') for USERSATISFY indicates that the survey respondents were satisfied with the new BIS or expect to be so (depending on the question or department). According to reliability tests, data on variables associated with each factor category in Table 1 are internally consistent with computed standardized Cronbach $\alpha$ values $>0.7$. Results of the five regression sub-models are as follows.

\subsection{Sub-Model (1)}

According to the regression results for sub-model (1), user-friendliness and system reliability exerted statistically significant positive impact on the new BIS's perceived usefulness (Table 2: $b_{11}=0.242, p<0.05, b_{12}=0.277, p$ $<0.05$ ). Since (1), (2) and (3) are reduced forms and the same explanatory variables enter into the right hand side of each equation, the $\mathrm{R}^{2}$ for any particular regression can be interpreted as a measure of goodness-of-fit relative to the other two relationships. The (adjusted) $\mathrm{R}^{2}$ value displayed in Table 2 therefore indicates that, holding constant the effects of user-friendliness and system reliability on perceived ease of use and expected ability to meet customer information needs under models (2) and (3), 28.7\% of the data variation in perceived usefulness was explained by user-friendliness and system reliability in equation (1). If (following the approach of Liao and Cheung 2001, 2002) we interpret the regression coefficients as impact multipliers, a unit increase in user-friendliness would produce a positive effect on perceived usefulness equal to $87 \%(0.242 / 0.277=0.874)$ of the effect from a unit increase in system reliability.

In sum, the empirical results for sub-model (1) suggest that perceived usefulness of the new BIS is significantly affected by whether the system is able to instill a feeling of friendliness in end-users and that the influence of reliability was such that end-users would perceive the new BIS to enhance retail banking operations if confident that the high-technology would not go awry or break down at critical moments. Hypothesis H1 is therefore supported by the survey data.

Table 2 Regression Results for Sub-Model (1)

\begin{tabular}{lcccccc}
\hline & \multicolumn{2}{c}{ Unstandardized Coefficients } & $\begin{array}{c}\text { Standardized } \\
\text { Coefficients }\end{array}$ & t-statistic & Sig. \\
\hline Sub-Model 1 & & $\mathrm{B}$ & Std. Error & & & \\
& $\mathrm{a}_{1}$ & 3.300 & 0.628 & & 5.257 & 0.000 \\
& $\mathrm{~b}_{11}$ & 0.242 & 0.099 & 0.314 & 2.441 & 0.018 \\
& $\mathrm{~b}_{12}$ & 0.277 & 0.116 & 0.307 & 2.385 & 0.020 \\
\hline
\end{tabular}

$\mathrm{F}=11.49(57,2)$, Sig. $0.000, \mathrm{R}^{2}=0.287$ 


\subsection{Sub-Model (2)}

According to the regression results for sub-model (2), user-friendliness and system reliability exerted statistically significant positive impact on the new BIS's perceived ease of use (Table $3: b_{21}=0.578, p<0.01, b_{22}=0.289$, $\mathrm{p}<0.01$ ). The (adjusted) $\mathrm{R}^{2}$ value displayed in Table 3 indicates that, holding the effects of user-friendliness and system reliability on perceived usefulness and expected ability to meet customer information needs under models (1) and (3) constant, $47.1 \%$ of the data variation in perceived ease of use is explained by user-friendliness and system reliability. Interpreting the regression coefficients as impact multipliers, a unit increase in user-friendliness would produce a positive effect on perceived ease of use equal to $200 \%(0.578 / 0.289=2.0)$ of the effect from a unit increase in system reliability.

In sum, the empirical results suggest that perceptions regarding ease of use of the new BIS are significantly predicated on user-friendliness and system reliability. In particular, it is important to consider ease of use in the sense that because of personal contact and immediacy, individuals assigned to retail banking (and other service-oriented business activities) are often reluctant to rely on new IT to any extent unless they perceive it to be easy to use for themselves and their clients. Hypothesis $\mathrm{H} 2$ is therefore supported by the survey data.

Table 3 Regression Results for Sub-Model (2)

\begin{tabular}{|c|c|c|c|c|c|c|}
\hline \multirow{2}{*}{ Sub-Model 2} & & \multicolumn{2}{|c|}{ Unstandardized Coefficients } & \multirow{2}{*}{$\begin{array}{c}\text { Standardized } \\
\text { Coefficients }\end{array}$} & \multirow[t]{2}{*}{ t-statistic } & \multirow[t]{2}{*}{ Sig. } \\
\hline & & $\mathrm{B}$ & Std. Error & & & \\
\hline & $\mathrm{a}_{2}$ & 1.230 & 0.747 & & 1.646 & 0.105 \\
\hline & $b_{21}$ & 0.578 & 0.118 & 0.542 & 4.890 & 0.000 \\
\hline & $b_{22}$ & 0.289 & 0.138 & 0.232 & 2.093 & 0.041 \\
\hline
\end{tabular}

$\mathrm{F}=25.36(57,2)$, Sig. $0.000, \mathrm{R}^{2}=0.471$

\subsection{Sub-Model (3)}

According to the regression results for sub-model (3), user-friendliness and system reliability exerted statistically significant positive impact on the new BIS's expected ability to meet customer information needs (Table 4: $\mathrm{b}_{31}$ $\left.=0.271, \mathrm{p}<0.05, \mathrm{~b}_{32}=0.362, \mathrm{p}<0.05\right)$. The adjusted $\mathrm{R}^{2}$ value displayed in Table 4 indicates that, holding the effects of user-friendliness and system reliability on perceived usefulness and perceived ease of use under models (1) and (2) constant, $25.2 \%$ of the data variation in expected ability to meet customer information needs was explained by user-friendliness and system reliability. Interpreting the regression coefficients as impact multipliers, a unit increase in user-friendliness would produce a positive effect on expected ability to meet customer information needs equal to $75 \%$ $(0.271 / 0.362=0.749)$ of the effect from a unit increase in system reliability.

In sum, the empirical findings suggest that the new BIS is operationally friendly and reliable. This contributes significantly toward expectations that it would meet the needs and requirements of retail account-holders for information. Hypothesis H3 is therefore supported by the survey data.

Table 4 Regression Results for Sub-Model (3)

\begin{tabular}{|c|c|c|c|c|c|c|}
\hline & & Unstand & Coefficients & Standardized & t-statistic & Sig. \\
\hline Sub-Model 3 & & B & Std. Error & & & \\
\hline & $\mathrm{a}_{3}$ & 2.459 & 0.833 & & 2.952 & 0.005 \\
\hline & $b_{31}$ & 0.271 & 0.132 & 0.271 & 2.054 & 0.045 \\
\hline & $b_{32}$ & 0.362 & 0.154 & 0.310 & 2.351 & 0.022 \\
\hline
\end{tabular}

$\mathrm{F}=9.587(57,2)$, Sig. $0.000, \mathrm{R}^{2}=0.252$ 
Considering the results for level one as a whole, comparison of the (adjusted) $\mathrm{R}^{2}$ for equations (1), (2) and (3) suggests that under the interpretation presented above, the effects of user-friendliness and system reliability are empirically most stable with regard to perceived ease of use, followed (in approximately equal magnitude) by perceived usefulness and expected ability to meet customer information needs. The individual impact of user-friendliness is highest in the direction of perceived ease of use, followed (in approximately equal magnitude) by expected ability to meet customer information needs and perceived usefulness. Similarly, the individual impact of system reliability is highest in the direction of expected ability to meet customer information needs, followed (in approximately equal magnitude) by perceived ease of use and perceived usefulness. If we bring system up-grading and cost-benefit considerations into account, a future increase in resources to enhance user-friendliness and system reliability would be likely to produce effects in the order indicated.

\subsection{Sub-Model (4)}

In sub-model (4), the coefficient regression results showed strong positive impact on end-user satisfaction. Perceived usefulness was found to exert a statistically significant effect (Table 5: $b_{41}=0.513, p<0.01$ ), and similarly for perceived ease of use (Table $5: b_{42}=0.398, p<0.01$ ) and expected ability to meet customer information needs (Table 5: $\mathrm{b}_{43}=0.257, \mathrm{p}<0.05$ ). The (adjusted) $\mathrm{R}^{2}$ value suggested that $58.9 \%$ of the data variation in end-user satisfaction was explained by perceived usefulness, perceived ease of use and expected ability to meet customer information needs (Table 5). Again following the approach of Liao and Cheung (2001, 2002), marginal rates of substitutions (MRS) can be calculated from the regression coefficients. Holding end-user satisfaction constant, a unit decrease in perceived usefulness must be compensated by a $130 \%\left(b_{41} / b_{42}=0.513 / 0.398=1.3\right)$ increase in perceived ease of use. Similarly, a unit decrease in perceived usefulness must be compensated by a $200 \%\left(b_{41} / b_{43}=0.513 / 0.257=2.0\right)$ increase in expected ability to meet customer information needs, if end-user satisfaction is not to change. A unit decrease in perceived ease of use must be compensated by a $150 \%\left(b_{42} / b_{43}=0.398 / 0.257=1.5\right)$ increase in expected ability to meet customer information needs, if end-user satisfaction is not to change.

In sum, the empirical results suggest that when perceived usefulness, perceived ease of use and expected ability to meet customer information needs are present to a significant degree, end-users would tend to feel favorably disposed towards the new BIS. Hypothesis H4 is therefore supported by the survey data.

Table 5 Regression Results for Sub-Model (4)

\begin{tabular}{ccccccc}
\hline & \multicolumn{2}{c}{ Unstandardized Coefficients } & $\begin{array}{c}\text { Standardized } \\
\text { Coefficients }\end{array}$ & t-statistic & Sig. \\
\hline Sub-Model 4 & & $\mathrm{~B}$ & Std. Error & & & \\
& $\mathrm{a}_{4}$ & -1.114 & 0.857 & & -1.300 & 0.199 \\
& $\mathrm{~b}_{41}$ & 0.513 & 0.126 & 0.376 & 4.062 & 0.000 \\
& $\mathrm{~b}_{42}$ & 0.398 & 0.098 & 0.403 & 4.052 & 0.000 \\
& $\mathrm{~b}_{43}$ & 0.257 & 0.098 & 0.244 & 2.609 & 0.012 \\
\hline
\end{tabular}

$\mathrm{F}=26.797$ (57, 2), Sig.0.000, $\mathrm{R}^{2}=0.589$

\subsection{Sub-Model (5)}

Regression analysis of sub-model (5) revealed that end-user satisfaction exerted a statistically significant positive impact on the new BIS acceptance (Table 6: $b_{51}=0.57, p<0.01$ ). We can interpret this result as following from the fact that the benefits of the system would enter mainly via applications and operations on the part of the bank's employees, both by themselves and in the capacity (where appropriate) of survey proxies for retail account-holders. Since the (adjusted) $\mathrm{R}^{2}$ indicated that $42.6 \%$ of the data variation in system success can be explained by user satisfaction (Table 6), hypothesis H5 is also supported by the survey data. 
Table 6 Regression Results for Sub-Model (5)

\begin{tabular}{|c|c|c|c|c|c|c|}
\hline \multirow{2}{*}{\multicolumn{2}{|c|}{ Sub-Model 5}} & \multicolumn{2}{|c|}{ Unstandardized Coefficients } & \multirow[t]{2}{*}{$\begin{array}{c}\text { Standardized } \\
\text { Coefficients }\end{array}$} & \multirow[t]{2}{*}{ t-statistic } & \multirow[t]{2}{*}{ Sig. } \\
\hline & & B & Std. Error & & & \\
\hline & $a_{5}$ & 3.012 & 0.535 & & 5.630 & 0.000 \\
\hline & $b_{51}$ & 0.570 & 0.087 & 0.653 & 6.564 & 0.000 \\
\hline
\end{tabular}

$\mathrm{F}=43.09(57,2)$, Sig. $0.000 \mathrm{R}^{2}=0.426$

\section{Concluding Observations}

This paper extends the TAM to empirically evaluate the acceptance of new BIS in a representative banking group in a representative international financial centre. Useful information was obtained by a survey tailored to specific circumstances and staff functions. Perceived usefulness, perceived ease of use and expected ability to meet customer information needs were identified as statistically significant determinants of end-user satisfaction, usage, and system acceptance. The mediating role of usage suggests that acceptance by bank staff is more likely if they should find or feel that using the new BIS would increase performance, be operationally convenient, and that it can be expected to satisfy customers in the sense of meeting their information needs and requirements. Since improvements in the direction of end-user satisfaction were found to encourage greater usage and system success, these findings highlight the importance of psychological considerations in BIS acceptance. In particular, involvement in system building would tend to shift preferences in favor of endorsement (thereby increasing usage and acceptance) so that active participation of prospective end-users should be encouraged from the early stages of design and implementation.

Since the new BIS is accepted on perceptions of usefulness, ease of use and meeting customer information requirements, our empirical results imply that under given conditions pair-wise tradeoffs exist between the latter factors. For example, in planning future system enhancement corporate strategists may be willing to live with a higher degree of operational complexity, if the latest hardware and software can deliver more efficient and effective use of information in management and control. The empirical importance of perceived ease of use suggests that end-users possessed of clearer and deeper knowledge of new system capabilities would be better able to exploit them and contribute to more ready acceptance. We may therefore expect training to increase perceptions of ease of use (and user-friendliness) to make a substantial contribution to successful BIS implementation. Similarly, greater user knowledge and experience increase the ability to learn by doing which would then serve to demystify the subject among other members of the firm or organization. Individuals with insufficient knowledge tend to be reluctant to use new business systems to a degree commensurate with the minimization of operating cost thus defeating the purpose of IT investment. As a result, training would be particularly effective in fostering staff self-confidence and heightening perceptions of new BIS capabilities. In addition, since system reliability was found to exert positive and statistically significant effects on perceived usefulness, perceived ease of use and expected ability to meet customer information needs, quality vendor support, and the provision of effective post-installment validation checks would encourage BIS acceptance.

The relationships between system characteristics and end-user satisfaction are a matter of on-going research. On a general level, this paper suggests that it would be fruitful to extend the TAM to a multi-level analysis under which perceived usefulness and perceived ease of use enter as immediate determinants of user satisfaction, system usage and acceptance, with perceptions being in turn hypothesized to depend on technical and functional factors such as user-friendliness and system reliability. Depending on the purpose of the BIS, additional immediate determinants (such as expected ability to meet customer information requirements in the present case of a service-oriented application) can be added on the same level as perceived usefulness and perceived ease of use. Similarly, other technical and computer-architectural considerations such as time-asymmetry (Cheung and Liao 2002) can be added to the level containing system characteristics.

\section{Suggestions for Future Research}

Since our empirical results are obtained under clear ceteris paribus conditions, useful directions for future research in specific areas are also suggested. In particular, given that our survey was applied to a representative situ- 
ation in retail banking, a number of insights into new BIS acceptance in service-oriented firms and organizations follow. In particular, it was found that user-friendliness and system reliability would produce more stable effects on perceived ease of use than is the case with perceived usefulness and expected ability to meet customer information needs. It follows that management effort can be most usefully directed towards encouraging user participation in the design and development of new customer-oriented BIS and to secure enhanced user-friendliness and system reliability. Parallel education and training programs should aim to increase staff awareness of system applications and emphasize the benefits of being au fait with the latest developments as well as to focus on improving the individual's IT self-efficacy. On the other side of the market, software developers and vendors would find it profitable to emphasize ease of use as a design objective pointing to the empirically-grounded argument that no matter how good the latest IT is - to be successful it would require people to accept it and use it.

We may conclude with a technical observation. Concomitant with the extension of the TAM to a multi-level analysis, two potentially fruitful modeling and estimation techniques are suggested. The first is the analytical hierarchy process (AHP) by Saaty (1996) which would be immediately applicable to formalize and estimate the relative importance of factors and variables within a given level. The second is the LISREL technique (Joreskog and Sorbom 1993, Byrne 1998), under which inter-level and intra-level structural relationships and their corresponding parameters and covariance relationships can be readily estimated, together with informative goodness-of-fit statistics is another avenue for future research in this area.

\section{References}

1. Aaker, D.A., Kumar, V. and Day, G. S. (2001). Marketing Research, $7^{\text {th }}$ edition. New York: Wiley.

2. Abdul-Gader, A. (1996). The Impact of User Satisfaction on Computer-Mediated Communication Acceptance: A Casual Path Model. Information Resources Management Journal 9(1), 17-26.

3. Abdul-Gader, A. H. (1992). End-User Computing Success Factors: Further Evidence from a Developing Nation. Journal of End-User Computing 4(3), 4-13.

4. Adams, D. A., Nelson, R. R. and Todd, P. A. (1992). Perceived Usefulness, Ease of Use, and Usage of Information Technology: a Replication. MIS Quarterly 16(2), 227-247.

5. Bailey, J. E. and Pearson, S. W. (1983). Development as a Tool for Measuring and Analyzing Computer Satisfaction. Management Science 29(5), 530-545.

6. Baroudi, J.J., Olson, M.H. and Ibes, B. (1986). An Empirical Study of the Impact of User Involvement on System Usage and Information Satisfaction. Communications of the ACM 29(3), 232-238.

7. Byrne, B.M. (1998). Structural Equation Modeling with LISREL, PRELIS, and SIMPLIS. Mahwah NJ: Lawrence Erlbaum Associates.

8. Cheung, M.T. and Liao, Z. (2002). Time Asymmetry in Business Process, Communications of the ACM 45(5), 107-108.

9. Davis, F. D. (1986). A Technology Acceptance Model for Empirically Testing New End-user Information Systems: Theory and Results. Cambridge MA: Sloan School of Management.

10. Davis, F. D. (1989). Perceived Usefulness, Perceived Ease of Use, And User Acceptance of Information Technology. MIS Quarterly 13(3), 319-340.

11. Davis, F.D., Bagozzi, R.P. and Warshaw, P.R. (1989). User Acceptance of Computer Technology: A Comparison of Two Theoretical Models. Management Science 35(6), 982-1002.

12. DeLone, W. H. (1988). Determinants of Success for Computer Usage in Small Firms. MIS Quarterly 12(1), 51-61.

13. Dishaw, M.T. and Strong, D.M. (1999). Extending the Technology Acceptance Model with Task-Technology Fit Constructs. Information and Management 36(1), 9-21.

14. Eccles, R.G. (1991). The Performance Measurement Manifesto. Harvard Business Review 69(1), $131-137$.

15. EinDor, P. and Jones, C. R. (1985). Information Systems Management. Lexington MA: D.C. Heath.

16. Feigenbaum, A.V. (1991). Total Quality Control. New York: McGraw-Hill.

17. Fishbein, M. and Azjen, I. (1975). Belief, Attitudes, Intention, and Behavior. New York: Addison-Wesley.

18. Garvin, D.A. (1988). Managing Quality: The Strategic and Competitive Edge. New York: Free Press.

19. Gatain, A.W. (1994). Is User Satisfaction a Valid Measure of System Effectiveness? Information and 
Management 26(3), 113-131.

20. Ives, B. and Olson, M. (1984). User Involvement and MIS Success: a Review of Research. Management Science 30(5), 586-603.

21. Joreskog, K. and Sorbom, D. (1993). LISREL 8: Structural Equation Modeling with the SIMPLIS Command Language. Chicago: Scientific Software International Inc.

22. Laudon, K.C. and Laudon, J.P. (2002). Management Information Systems: Managing the Digital Firm $7^{\text {th }}$ edition. Upper Saddle River NJ: Prentice Hall.

23. Liao, Z. and Cheung, M.T. (2001). Internet-based e-shopping and Consumer Attitudes: An Empirical Study. Information and Management 38(5), 299-306.

24. Liao, Z. and Cheung, M.T. (2002). Internet-based e-Banking and Consumer Attitudes: An Empirical Study. Information and Management 39(4), 283-295.

25. Lucas, H. C. (1972). Performance Evaluation and the Management of Information Systems. Database 4(1), $1-8$.

26. Lucas, H.C. and Spitler, V. (2000). Implementation in a World of Workstations and Networks. Information and Management 38(2), 119-128.

27. Myers, B. L. (1997). A Comprehensive Model for Assessing the Quality and Productivity of the Information Systems Function: Toward a Theory for Information System Assessment. Information Resource Management Journal 10(1), 6-25.

28. Plouffe, C.R., Hulland, J.S. and Vanderbosch, M. (2001). Research Report: Richness versus Parsimony in Modeling Technology Adoption Decisions - Understanding Marchant Adoption of a Smart Card-Based Payment System. Information Systems Research 12(2), 208-222.

29. Powers, R. F. and Dickson, G.W. (1973). MIS Project Management: Myths, Opinions and Reality. California Management Review 15(3), 147-156.

30. Raymond, L. (1987). Validating and Applying User Satisfaction as a Measure of MIS Success in Small Organizations. Information and Management 12(3), 173-179.

31. Saaty, T.L. (1996). The Analytic Network Process. Pittsburg PA: RWS Publications.

32. Soh, C.P.P., Yap, C.S. and Raman, K.S. (1992). Impacts of Consultants on Computerization Success in Small Businesses. Information and Management 22(5), 309-319.

33. Straub, D., Limayem, M. and Karahanna-Evaristo, E. (1995). Measuring System Usage: Implications For IS Theory Testing. Management Science 41(8), 1328-1342.

34. Szajna, B. (1996). Empirical Evaluations of the Revised Technology Acceptance Model. Management Science 42(1), 85-92.

35. Venkatesh, V. and Davis, F.D. (2000). A Theoretical Extension of the Technology Acceptance Model: Four Longitudinal Studies. Management Science 46(2), 186-204. 
Notes 